\title{
TOMADA DE DECISÃO RACIONAL E EXPERIENCIAL NO PROJETO DE PRODUTOS
}

\author{
RATIONAL AND EXPERIENTIAL DECISION-MAKING IN \\ PRODUCT DESIGN
}

\author{
Valentina Marques da Rosa', Roberta Rech Mandelli', Priscila G. Brust-Renck ${ }^{2}$ \\ Leandro Miletto Tonetto'
}

RESUMO: Diversos estudos referentes à tomada de decisão permitem observar que profissionais utilizam um dos dois sistemas para definir seus projetos: o racional (sistema inferencial ou analítico que opera através de regras de raciocínio, relativamente livres de emoção) ou experiencial/intuitivo (aprendizagem ou sistema automático que está intimamente associado a elementos emocionais). Profissionais de áreas relacionadas à criatividade podem muitas vezes precisar tomar decisões sem muitos dados concretos, necessitando utilizar sua intuição. Com isso em mente, este artigo apresenta um estudo cujo objetivo é avaliar o processo de tomada de decisão de designers de produto em comparação a outros profissionais que atuam na mesma área (engenheiros e arquitetos). Com esse propósito, foi utilizado o Inventário Racional-Experimental (Rational-Experiential Inventory). De forma geral, os resultados mostraram uma diferença significativa entre engenheiros e outros profissionais: eles tomam decisões baseando-se em um sistema mais racional e menos experiencial do que arquitetos e designers, mas diferenças consistentes entre designers e arquitetos não foram identificadas.

PALAVRAS-CHAVE: Tomada de Decisão no Design; Intuição no Design; Design de Produto; Inventário Racional-Experimental.

ABSTRACT: Several studies on decision-making allow us to observe that professionals use one of two systems to define their projects: rational (i.e., inferential or analytical system that operates by rules of reasoning, relatively affect-free) or experiential/ intuitive (i.e., learning or automatic system that is intimately associated with affect). Professionals from creativity related areas may often need to make decisions without much concrete data, which requires the use of their intuition. This paper presents a study that aims to evaluate the reasoning process of making decisions by product designers in comparison to other professionals that work in the same field (i.e., engineers and architects). For this purpose, we used the Rational-Experiential Inventory (REI). Overall, our results show a significant difference between engineers and the other professionals: they make decisions based on a more rational and less experiential system than architects and designers, although we didn't find huge differences between designers and architects.

KEYWORDS: Design Decision-Making; Design Intuition; Product Design; RationalExperiential Inventory.

\section{INTRODUÇÃO}

Quando confrontados com várias opções, designers passam por um processo cognitivo definido como julgamento, que possibilita a escolha entre alternativas (SIMON, 1996). Diversos estudos sobre julgamento e tomada de decisão permitem observar que as pessoas utilizam um dos dois sistemas (teorias de processamento duplo) para definir seus projetos (EPSTEIN, 1994): racional (sistema inferencial ou analítico que opera através de regras de raciocínio, relativamente livres de emoção) ou experiencial/intuitivo (aprendizagem ou sistema automático que está intimamente associado a elementos emocionais). Compreender a tomada de decisão de designers

\section{How to cite this article:}

ROSA, V. M.; MANDELLI, R. R.; BRUST-RENCK, P. G.; TONETTO, L. M. Tomada de decisão racional e experiencial no projeto de produtos. Gestão e Tecnologia de Projetos, São Carlos, v. 13, n. 1, p. 75-84, 2018. http://dx.doi.org/10.11606/gtp.v13i1.137621

Fonte de financiamento: Coordenação de Aperfeiçoamento de Pessoal de Nível Superior (Capes) e Conselho Nacional de Desenvolvimento Científico e Tecnológico (CNPq)

Conflito de interesse: Declaram não haver Submetido em: 01/09/2017 Aceito em: 18/09/2017 
de produto é uma maneira de entender como funcionam seus processos mentais, se eles confiam mais em suas experiências (sistema experiencial/ intuitivo) ou em suas habilidades de raciocinar acerca de um tema (sistema racional) para tomar decisões em um projeto.

Assumindo que o sistema experiencial/intuitivo é baseado na experiência pregressa, profissionais com diferentes formações acadêmicas podem ter perfis distintos nos processos de julgamento e tomada de decisão (TONETTO; TAMMINEN, 2015). Nessa direção, o objetivo geral da pesquisa apresentada foi identificar a maneira como profissionais tomam decisões racionais e experienciais em projetos de produto. Designers, engenheiros e arquitetos, por exemplo, desenvolvem projetos que implicam em decisões de alto impacto e estudos que comparam a forma como esses indivíduos fazem suas escolhas ainda são escassos.

A hipótese levantada neste estudo é de que designers tomam decisões de maneira diferente dos outros profissionais. Design é conhecido por sua particular cultura de projeto, frequentemente relacionada a criatividade e inovação. Por isso, designers podem precisar pensar de maneira mais intuitiva do que outros profissionais de áreas nas quais os problemas estruturados, que envolvem o uso do raciocínio, são os mais comuns na prática. O objetivo desta investigação foi avaliar o processo intuitivo de tomada de decisão dos designers em comparação com outros profissionais que trabalham em projetos que envolvem novos produtos. Com essa finalidade, foi realizada uma pesquisa utilizando o Inventário Racional-Experimental (RationalExperiential Inventory - REI), descrito na próxima sessão.

O estudo justifica-se, em nível teórico, pela necessidade de compreender de que forma processos intuitivos, já mapeados pela psicologia cognitiva, podem ser entendidos na prática do design. Assim, será possível entender um dos aspectos centrais da cultura de projeto do design, a intuição frente às incertezas trazidas no projeto, em comparação com outras áreas projetuais.

No âmbito aplicado, a compreensão desse processo auxiliará na formatação de ferramentas que facilitem a tomada de decisão dos designers frente à incerteza, bem como oferecer bases de conhecimento para a realização de treinamentos de uso da intuição para designers, como proposto na área da medicina por The American Board of Scientific Medical Intuition.

\section{REFERENCIAL TEÓRICO}

\section{Intuição e tomada de decisão}

O processo de projeto de produtos envolve uma série de mecanismos cognitivos empregados pelos designers. A resolução de problemas, a criatividade e a tomada de decisão são alguns dos principais processos psicológicos envolvidos na forma como designers pensam suas soluções de projeto. O pensar e o agir da cultura de projeto do design são diferenciados de outras áreas projetuais (TONETTO; TAMMINEN, 2015) como a arquitetura e a engenharia, e são entendidos comumente como direcionados para a criatividade e inovação.

Profissionais de áreas como a engenharia usualmente fundamentam suas decisões no desenvolvimento de produtos em dados concretos e quantificáveis. Essas decisões são entendidas como baseadas em um mecanismo psicológico denominado raciocínio, que é lógico, serial e ordenado (KAHNEMAN, 2003).

Por outro lado, profissionais de áreas voltadas para a criatividade, como o design, frequentemente tomam decisões de projeto de produto sem a presença de dados concretos sobre a realidade, já que são diariamente forçados a gerar soluções para problemas ainda não resolvidos. Nesses casos, é comum que entre em ação um processo denominado intuição, entendida, nas ciências cognitivas, como uma forma de julgar alternativas 
de projeto com base em impressões difusas, de base emocional e, muitas vezes, não passíveis de mensuração (KAHNEMAN, 2003).

Simon e outros pesquisadores, incluindo Kahneman (2003) dedicaram esforços para compreender como a mente humana funciona e toma decisões frente à disponibilidade limitada de informações no cotidiano. As diferenças entre racionalidade e intuição têm sido foco na pesquisa em psicologia nas últimas décadas. Essa diferença foi inicialmente descrita por Epstein (1994) através de dois modos de processamento da informação: um sistema racional e outro de cunho experiencial e regido pela emoção. Sloman (1996) também descreveu tais diferenças, mas como resultado de dois tipos de indivíduos: aqueles que tendem a tomar decisões baseadas na emoção e os que o fazem baseados no processamento racional.

A evolução de pesquisas na área trouxe a ideia de que o termo racionalidade não representa o oposto de intuição. Muitas vezes, decidir de forma rápida e intuitiva pode ser desejável e racional. Nessa direção, Kahneman (2003) descreveu o processo de tomada de decisão com base em dois sistemas. As ações do Sistema 1 (intuitivo) são rápidas, associativas, implícitas, emocionalmente carregadas, guiadas por hábitos e de difícil controle e modificação. Por outro lado, o Sistema 2 (raciocínio) é lento, requer muito esforço cognitivo e é guiado por regras. Decidir intuitivamente pode ser desejado, de modo que o termo "racionalidade limitada" foi cunhado desde os estudos de Simon na década de 1950 e permanece em uso até os dias atuais.

A maior parte dos indivíduos prefere utilizar intuição a raciocínio, mas é também verdade que algumas pessoas podem ter tendência maior a se engajarem em atividades que exigem altas demandas cognitivas (SLOMAN, 1996). O likelihood elaboration model (CACIOPPO et al., 1986) indica que as pessoas podem seguir duas rotas para a tomada de decisão: a central e a periférica. A rota central é focada na decisão e em sua avaliação concreta (Sistema 2), enquanto a periférica tende a levar em consideração aspectos que não são centralmente relevantes para o problema (Sistema 1), e envolvem baixo esforço cognitivo.

Comumente o designer não tem todas as informações necessárias para tomar decisões seguras, mas necessita decidir mesmo assim. Na busca de solução para esses problemas, entram em ação variáveis diversas que vêm sendo investigadas por meio de escalas como: o grau em que as pessoas buscam tomar decisões racionais (PACCINI; EPSTEIN, 1999) ${ }^{1}$; o quanto se baseiam em suas próprias experiências de forma intuitiva (PACCINI; EPSTEIN, 1999)²; em que medida buscam e avaliam diferentes alternativas antes de tomar uma decisão (TURNER et al., 2012)3; o quão difícil é para elas fazer uma escolha (TURNER et al., 2012) de pensamento "mente aberta" (STANOVICH; WEST, 2007)5. Todos esses processos evidentemente estão relacionados ao tipo de pensamento empregado pelos profissionais (VOLPENTESTA et al., 2011) ${ }^{6}$.

Aqui se destaca novamente a relevância de mapear as formas de pensamento utilizadas pelos profissionais de distintas áreas no processo de elaboração de um novo produto. A possibilidade de identificar em qual sistema se concentram suas escolhas é um passo importante para entender como se dá esse processo projetual e de que maneira a formação acadêmica pode ter influência na concepção de determinado perfil de projetista. Vislumbra-se aqui a possibilidade de compreensão das limitações provocadas por escolhas pautadas em certo tipo de processo cognitivo, bem como suas consequências projetuais. Uma vez que se tenha informações suficientes sobre esses perfis de projetistas, a visão de como um profissional se aproxima de determinado problema projetual pode se tornar mais clara.

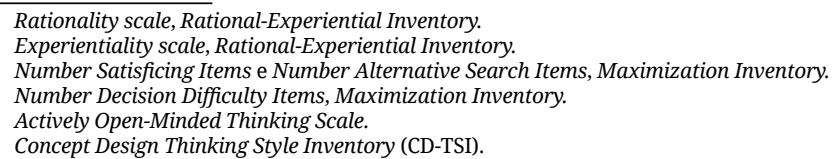




\section{O processo de design de produtos}

Existem diferentes visões a respeito dos processos de projeto. Simon (1996) enfatizou em seu trabalho a importância e relevância de um estudo referente à ciência do projeto. É importante destacar que o autor defendia a ideia de que qualquer pessoa que atue buscando aprimorar situações atuais está projetando. Ao falar sobre a ciência do projeto, Simon (1996) retoma o conceito de racionalidade limitada quando explica que apenas em casos triviais, ou seja, em problemas simplórios, é possível definir uma alternativa ótima. $\mathrm{O}$ autor afirma que os processos projetuais costumam buscar soluções satisfatórias para determinado problema, uma vez que existem muitas limitações para encontrar o que seria considerada a melhor alternativa.

Para isso, Simon (1996) define que o processo de projeto deve iniciar com a geração de alternativas para depois testá-las contra um arranjo de requisitos e condições. Tais testes podem ocorrer diversas vezes, visto que demonstrarão as consequências indiretas. A partir de ciclos de testes, o projetista descarta soluções menos satisfatórias até encontrar uma condizente com os prérequisitos da resolução. Isso corrobora com o que foi proposto por Baxter (2011), que percebe o processo como uma atividade estruturada e ordenada, mas as ações que geram essas decisões não precisam seguir a mesma estrutura reguladora. Para o autor, o processo se dá em etapas, em que cada uma compreende um ciclo de geração de ideais que em outro momento serão selecionadas. A organização dessas atividades em um projeto se dá de forma complexa e passa por diversos passos.

Para melhor definir um processo de projeto, Baxter (2011) estabelece quatro etapas no gerenciamento das atividades: ideias preliminares para um primeiro teste de mercado; especificações de oportunidade e projeto, direcionando ao projeto conceitual; configurações do conceito para um segundo teste de mercado, que, se bem sucedido, passa para a configuração do produto; e produção (se aprovado, passa-se para desenhos detalhados para fabricação e protótipo). Após a aprovação do protótipo se considera encerrado o processo de desenvolvimento de um produto, que segue para a produção. Porém, é importante ressaltar que o autor acredita que esse processo não se dá de maneira linear, de forma que muitas vezes uma etapa será omitida ou pulada, enquanto outras terão que ser repetidas inúmeras vezes. As ideias surgem de forma inesperada e, até o final do projeto, vão e voltam muitas vezes, em um processo interativo. Ou seja, de forma não muito distinta das ideias apresentadas por Simon, Baxter (2011) defende que esse processo de design de produtos se dá através da geração de alternativas, e quanto mais alternativas forem produzidas e testadas de acordo com as especificações de projeto anteriormente definidas, mais perto se chegará de uma solução descrita pelo autor como ideal.

Trazendo uma visão distinta sobre o processo projetual, Schön (2000) propõe que o projeto acontece através do que denomina prática-reflexiva. Para o autor, o processo começa a partir de uma problemática real, incerta e complexa, que se gostaria de modificar. Com base nisso, a atividade é principiada com o objetivo de modificar a situação inicial considerada problemática. Porém, Schön (2000) reconhece que o processo de projeto envolve várias incerteza e que muitas vezes não é resolvido a partir de procedimentos pré-estabelecidos. Dessa forma, o autor defende que grande parte do processo de projeto ocorre através de reflexão-na-ação, ou seja, um processo de tentativa e erro que ocorre durante a prática, no qual para-se para refletir sobre o que foi feito, se necessário diversas vezes, até a construção de uma solução considerada adequada. Schön (2000) defende que é através do desenho e da conversa que se constrói um projeto, e que essas ferramentas constituem o que denomina de linguagem do processo de projeto.

Para Dorst (2003) há uma dificuldade referente à resolução quando os problemas são daárea de design, visto que não são completamente determinados e nem totalmente livres. Isso corrobora com que o foi proposto por Rittel e Weber (1973) a respeito dos problemas de design serem mal-estruturados. Para 
lidar com isso, Dorst (2003) afirma que o profissional deve interpretar esses problemas de forma objetiva ou subjetiva. De forma geral, pode-se dizer que interpretações objetivas estão ligadas à visão de Simon de problemas de design, enquanto as subjetivas estão mais relacionadas às ideias de Schön. O objetivo é que o profissional possa compreender a forma mais adequada de tratar o problema na determinada etapa do processo em que ele se encontra, o que corrobora com a ideia de Bonsiepe (1984), ao apresentar métodos e técnicas projetuais que orientam o projeto de produtos em perspectiva experimental. Apesar de sugerir uma estrutura metodológica, o autor indica, também, que o processo deve ser marcado por uma liberdade relativa no que se refere à escolha de caminhos alternativos para o projeto.

Percebe-se que o ponto em comum no que foi proposto pelos autores está na resolução de problemas através da busca de alternativas. As diferenças nas duas visões podem ser tratadas como problemas epistemológicos, já que se apresentam como visão positivista e fenomenológica, respectivamente. Além disso, Dorst (2003) apresenta o conceito de co-evolução, no qual o desenvolvimento e o refinamento do problema de design e de suas soluções ocorrem simultaneamente. Os espaços do problema e da solução não são tratados de forma separada e o design dedica-se à evolução de ambos. Esta ideia corrobora com a visão de Baxter (2011), que afirma que o processo de desenvolvimento de produtos lida com problemas multifatoriais e nebulosos, de forma que a condução do desenvolvimento do produto é essencial para determinar seu possível sucesso ou fracasso.

Entende-se assim que, durante o processo de design de produtos, o profissional tem espaço para tomar decisões baseadas no Sistema 1 (intuitivo), uma vez que esse processo costuma funcionar de forma aberta e subjetiva. Os problemas tendem a não ser bem estruturados, na mesma medida em que não se possui todas as informações necessárias para que as decisões fossem efetuadas apenas através do raciocínio. Dessa forma, a utilização de impressões intuitivas para a tomada de decisões ao longo de um processo projetual é inevitável.

\section{MÉTODO}

O método de investigação consistiu em uma enquete on-line. As questões foram relacionadas às características demográficas dos participantes e ao REI (PACINI; EPSTEIN, 1999), que consistiu em duas principais escalas: racionalidade $(\alpha=0,85)$, que correspondia ao estilo racional e analítico de pensar, e experiencialidade $(\alpha=0,89)$, que correspondia ao estilo intuitivo e afetivo de pensar. Cada escala inclui subescalas de habilidade e engajamento.

Medidas de habilidade referem-se a pensar lógica e analiticamente (habilidade racional; $\alpha=0,83$ ) ou a se basear em impressões e sentimentos intuitivos (habilidade intuitiva; $\alpha=0,80$ ). Medidas de engajamento referem-se à confiança em pensar de maneira lógica/analítica (engajamento racional; $\alpha=$ 0,67 ) ou em sentimentos (habilidade intuitiva; $\alpha=0,80$ ) quando se toma decisões. Cada escala é composta por 20 itens (10 por habilidade e 10 por engajamento), avaliados em uma escala de 5 pontos que varia de 1 (definitivamente não verdadeiro sobre mim) a 5 (definitivamente verdadeiro sobre mim).

Este foi um estudo descritivo e a amostragem foi realizada por conveniência. A amostra foi acessada por e-mail através da rede de contatos dos pesquisadores. Os critérios de exclusão foram: não ser graduado em uma das áreas investigadas (design, engenharia e arquitetura) ou nunca ter trabalhado no desenvolvimento de produtos.

As análises foram realizadas utilizando o IBM SPSS Statistics (Versão 21.0). Para testar as diferenças entre estilos de pensamento, foram conduzidos Testes-T. Para testar diferenças na formação profissional, foram utilizadas análises de variância univariada (Anova), cujas variáveis dependentes foram escalas e subescalas do REI. Como os resultados mostraram-se consistentes mesmo quando idade e gênero foram incluídos como covariáveis nas Anova, foram relatados apenas os efeitos principais. 


\section{DESENVOLVIMENTO}

\section{Resultados e discussão}

A amostra consistiu em vinte designers, trinta engenheiros e vinte arquitetos. No total, $64,3 \%$ dos participantes eram do sexo masculino e $35,7 \%$ do sexo feminino. A idade média dos participantes foi 36,9 anos (DP = 12,0).

A Tabela 1 indica os itens de cada subescala, médias e desvios-padrão para as três amostras e para o total. No entanto, o REI deve ser avaliado a partir das médias gerais por subescala (PACINI; EPSTEIN, 1999), o que pode ser observado na Tabela 2.

Tabela 1: Médias e desvios-padrão das escalas e subescalas do Inventário Racional Experiencial (Rational- Experiential Inventory)

\begin{tabular}{|c|c|c|c|c|c|c|c|c|c|}
\hline \multirow{2}{*}{$\frac{\pi}{\widetilde{J}}$} & \multirow{2}{*}{ Itens } & \multicolumn{2}{|c|}{ Arquitetura } & \multicolumn{2}{|c|}{ Engenharia } & \multicolumn{2}{|c|}{ Design } & \multicolumn{2}{|c|}{ Total } \\
\hline & & M & DP & M & DP & M & DP & M & DP \\
\hline \multirow{10}{*}{ 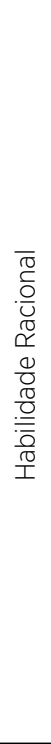 } & Eu tenho uma mente lógica. & 3,95 & 0,89 & 4,35 & 1,05 & 3,85 & 0,81 & 4,10 & 0,97 \\
\hline & Eu não sou um pensador muito analítico. & 2,10 & 0,97 & 1,55 & 0,96 & 2,05 & 0,94 & 1,86 & 0,98 \\
\hline & Eu não raciocino bem sob pressão. & 2,45 & 1,39 & 2,03 & 1,30 & 2,30 & 1,13 & 2,24 & 1,28 \\
\hline & $\begin{array}{l}\text { Eu sou muito melhor em resolver coisas logicamente que a } \\
\text { maioria das pessoas. }\end{array}$ & 3,42 & 1,02 & 4,10 & 0,87 & 3,20 & 0,89 & 3,64 & 0,98 \\
\hline & $\begin{array}{l}\text { Eu geralmente tenho razões claras e explicáveis para minhas } \\
\text { decisões. }\end{array}$ & 4,05 & 0,69 & 4,19 & 0,79 & 4,00 & 1,08 & 4,11 & 0,84 \\
\hline & $\begin{array}{l}\text { Não tenho nenhum problema em pensar sobre as coisas com } \\
\text { cuidado. }\end{array}$ & 4,50 & 0,76 & 4,32 & 0,91 & 4,37 & 1,01 & 4,38 & 0,89 \\
\hline & Eu não sou muito bom em resolver problemas complicados. & 2,10 & 1,17 & 1,55 & 0,72 & 1,65 & 0,67 & 1,74 & 0,88 \\
\hline & $\begin{array}{l}\text { Raciocinar cuidadosamente sobre as coisas não é um dos meus } \\
\text { pontos fortes. }\end{array}$ & 2,00 & 1,21 & 1,48 & 0,57 & 1,70 & 0,80 & 1,70 & 0,87 \\
\hline & $\begin{array}{l}\text { Usar lógica geralmente funciona bem para mim para resolver } \\
\text { problemas na minha vida. }\end{array}$ & 4,05 & 0,83 & 4,32 & 0,75 & 4,25 & 0,55 & 4,23 & 0,73 \\
\hline & $\begin{array}{l}\text { Eu não sou muito bom em resolver problemas que requerem } \\
\text { análise lógica cuidadosa. }\end{array}$ & 2,25 & 1,16 & 1,45 & 0,72 & 1,85 & 0,93 & 1,79 & 0,98 \\
\hline \multirow{10}{*}{ 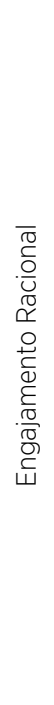 } & Eu prefiro problemas complexos a problemas simples. & 3,45 & 0,94 & 3,58 & 1,23 & 3,80 & 1,06 & 3,59 & 1,10 \\
\hline & $\begin{array}{l}\text { Tento evitar situações que requerem pensar profundamente } \\
\text { sobre alguma coisa. }\end{array}$ & 1,95 & 0,94 & 1,32 & 0,54 & 1,65 & 0,67 & 1,60 & 0,75 \\
\hline & $\begin{array}{l}\text { Pensar bastante e por um longo período sobre algo me dá pouca } \\
\text { satisfação. }\end{array}$ & 2,40 & 1,35 & 2,00 & 0,93 & 2,25 & 1,12 & 2,20 & 1,11 \\
\hline & Pensar não é o que eu chamaria de atividade agradável. & 1,65 & 0,99 & 1,32 & 0,83 & 1,35 & 0,59 & 1,43 & 0,83 \\
\hline & $\begin{array}{l}\text { Aprender novas maneiras de pensar seria muito atraente para } \\
\text { mim. }\end{array}$ & 4,58 & 0,51 & 4,45 & 0,72 & 4,35 & 0,88 & 4,45 & 0,72 \\
\hline & Eu gosto de desafios intelectuais. & 4,05 & 1,10 & 4,45 & 0,85 & 4,35 & 1,09 & 4,30 & 1,00 \\
\hline & Eu gosto de pensar em termos abstratos. & 3,15 & 1,23 & 3,03 & 1,25 & 3,50 & 1,00 & 3,19 & 1,18 \\
\hline & Não gosto de ter que pensar muito. & 1,85 & 0,93 & 1,48 & 0,77 & 1,55 & 0,60 & 1,61 & 0,79 \\
\hline & $\begin{array}{l}\text { Saber a resposta sem ter que entender o raciocínio por trás dela } \\
\text { é bom o suficiente para mim. }\end{array}$ & 1,75 & 0,85 & 1,45 & 0,72 & 1,80 & 1,11 & 1,64 & 0,89 \\
\hline & Eu gosto de resolver problemas que envolvam pensar bastante. & 4,05 & 1,15 & 4,16 & 0,86 & 4,10 & 0,91 & 4,10 & 0,95 \\
\hline
\end{tabular}


Tabela 1: Continuação

\begin{tabular}{|c|c|c|c|c|c|c|c|c|c|}
\hline \multirow{2}{*}{$\frac{\pi}{\sqrt[J]{J}}$} & \multirow{2}{*}{ Itens } & \multicolumn{2}{|c|}{ Arquitetura } & \multicolumn{2}{|c|}{ Engenharia } & \multicolumn{2}{|c|}{ Design } & \multicolumn{2}{|c|}{ Total } \\
\hline & & M & DP & M & $\mathrm{DP}$ & M & $\mathrm{DP}$ & M & DP \\
\hline \multirow{10}{*}{ 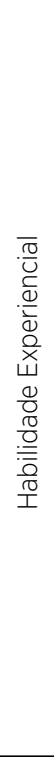 } & Eu acredito que devo confiar em meus pressentimentos. & 4,30 & 0,73 & 3,47 & 0,97 & 3,85 & 0,93 & 3,81 & 0,96 \\
\hline & Eu confio na primeira impressão que tenho das pessoas. & 3,65 & 0,99 & 3,10 & 1,11 & 2,80 & 1,11 & 3,17 & 1,12 \\
\hline & $\begin{array}{c}\text { Quanto a confiar nas pessoas, geralmente posso contar com meus } \\
\text { pressentimentos. }\end{array}$ & 4,05 & 0,76 & 3,35 & 1,14 & 3,21 & 0,92 & 3,52 & 1,04 \\
\hline & $\begin{array}{l}\text { Eu geralmente posso sentir quando uma pessoa está certa ou } \\
\text { errada, mesmo se eu não conseguir explicar como sei. }\end{array}$ & 3,50 & 0,95 & 3,19 & 1,25 & 3,05 & 0,83 & 3,23 & 1,07 \\
\hline & $\begin{array}{l}\text { Eu dificilmente erro quando ouço meus pressentimentos mais } \\
\text { profundos para encontrar uma resposta. }\end{array}$ & 3,20 & 0,95 & 3,29 & 1,04 & 3,30 & 1,08 & 3,27 & 1,02 \\
\hline & $\begin{array}{l}\text { Eu geralmente sigo meu instinto quando tenho que decidir por uma } \\
\text { linha de ação. }\end{array}$ & 3,55 & 1,19 & 2,45 & 1,21 & 3,50 & 0,95 & 3,04 & 1,24 \\
\hline & Eu não tenho um senso muito bom de intuição. & 1,75 & 0,85 & 2,71 & 1,13 & 2,15 & 0,59 & 2,30 & 1,00 \\
\hline & $\begin{array}{l}\text { Se eu tivesse que contar com meus pressentimentos, eu } \\
\text { frequentemente erraria. }\end{array}$ & 1,95 & 0,89 & 2,71 & 1,22 & 2,25 & 0,64 & 2,39 & 1,03 \\
\hline & $\begin{array}{l}\text { Eu suspeito que meus pressentimentos estão precisos com a } \\
\text { mesma frequência que estão imprecisos. }\end{array}$ & 2,85 & 1,09 & 2,94 & 1,18 & 3,35 & 0,88 & 3,04 & 1,08 \\
\hline & $\begin{array}{l}\text { Meus julgamentos repentinos provavelmente não são tão bons } \\
\text { quanto os da maioria das pessoas. }\end{array}$ & 2,45 & 0,94 & 2,40 & 0,89 & 2,40 & 0,75 & 2,43 & 0,85 \\
\hline \multirow{10}{*}{ 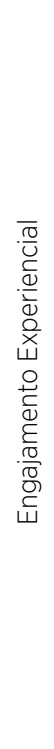 } & Eu gosto de confiar nas minhas impressões intuitivas. & 3,85 & 1,04 & 2,93 & 1,14 & 3,50 & 1,00 & 3,35 & 1,14 \\
\hline & $\begin{array}{l}\text { Eu não gosto de situações em que tenho que contar com minha } \\
\text { intuição. }\end{array}$ & 2,10 & 1,02 & 2,77 & 1,18 & 2,80 & 1,06 & 2,60 & 1,13 \\
\hline & Intuição pode ser uma maneira muito útil para resolver problemas. & 3,70 & 0,92 & 2,87 & 1,43 & 3,40 & 1,14 & 3,23 & 1,25 \\
\hline & $\begin{array}{l}\text { Eu não gostaria de depender de ninguém que se descreva como } \\
\text { um(a) intuitivo(a). }\end{array}$ & 2,85 & 1,23 & 3,39 & 1,41 & 3,10 & 1,17 & 3,19 & 1,28 \\
\hline & $\begin{array}{c}\text { Eu não acho uma boa ideia uma pessoa confiar em sua intuição para } \\
\text { decisões importantes. }\end{array}$ & 2,80 & 1,11 & 3,65 & 1,20 & 2,60 & 0,99 & 3,11 & 1,21 \\
\hline & $\begin{array}{l}\text { Eu acho que é tolice tomar decisões importantes } \\
\text { baseadas em sentimentos. }\end{array}$ & 2,11 & 1,28 & 3,00 & 1,21 & 2,45 & 1,10 & 2,63 & 1,23 \\
\hline & Tenho tendência a usar meu coração como guia para minhas ações. & 3,45 & 1,15 & 2,13 & 1,06 & 3,45 & 1,15 & 2,86 & 1,28 \\
\hline & $\begin{array}{l}\text { Eu geralmente não confio em meus sentimentos para ajudar a } \\
\text { tomar decisões. }\end{array}$ & 1,70 & 0,80 & 2,63 & 1,03 & 2,10 & 0,72 & 2,22 & 0,97 \\
\hline & $\begin{array}{l}\text { Eu acho que há momentos em que uma pessoa deve contar com } \\
\text { sua intuição. }\end{array}$ & 4,45 & 0,76 & 3,74 & 1,03 & 4,20 & 0,77 & 4,07 & 0,94 \\
\hline & $\begin{array}{l}\text { Usar meus pressentimentos geralmente funciona bem para mim ao } \\
\text { resolver problemas em minha vida. }\end{array}$ & 4,25 & 0,72 & 3,10 & 1,19 & 3,45 & 0,83 & 3,51 & 1,09 \\
\hline
\end{tabular}

Fonte: Resultados do Rational-Experiential Inventory

Conforme é possível observar na Tabela 1, diversos itens têm escala invertida. Por exemplo, o pensador analítico, na subescala "habilidade racional", deve atribuir resposta alta em "Não tenho nenhum problema em pensar sobre as coisas com cuidado" e resposta baixa em "Raciocinar cuidadosamente sobre as coisas não é um dos meus pontos fortes”. Uma vantagem de trabalhar com escalas que variam o padrão esperado de respostas é engajar os participantes e evitar o chute. Nessa direção, para o cálculo das médias gerais (Tabela 2), os itens invertidos foram recodificados no banco de dados, conforme instruções do REI (PACINI; EPSTEIN, 1999). 
Tabela 2: Médias e desvios-padrão das escalas e subescalas do Inventário Racional Experiencial (Rational- Experiential Inventory)

\begin{tabular}{lccccccccc}
\hline Formação & Arquitetura & Engenharia & Design & & Total \\
\hline Escalas e Subescalas & $M$ & DP & M & DP & M & DP & M & DP \\
\hline Racionalidade (geral) & 3,94 & 0,60 & 4,25 & 0,39 & 4,08 & 0,45 & 4,1 & 0,49 \\
\hline Engajamento Racional & 3,97 & 0,56 & 4,19 & 0,41 & 4,15 & 0,50 & 4,11 & 0,49 \\
\hline Habilidade Racional & 3,91 & 0,71 & 4,32 & 0,46 & 4,01 & 0,50 & 4,11 & 0,57 \\
\hline Experiencialidade (geral) & 3,77 & 0,46 & 3,04 & 0,67 & 3,42 & 0,50 & 3,36 & 0,64 \\
\hline Engajamento Experiencial & 3,74 & 0,58 & 2,83 & 0,74 & 3,50 & 0,63 & 3,28 & 0,77 \\
\hline Habilidade Experiencial & 3,80 & 0,48 & 3,25 & 0,70 & 3,35 & 0,45 & 3,43 & 0,62 \\
\hline
\end{tabular}

Fonte: Elaborado pelos autores

A Tabela 2 indica que, na escala geral de racionalidade, designers e engenheiros tendem a ter maiores médias, quando os resultados são comparados com seus desempenhos globais em experiencialidade [t (19) $=3,60, p=0,002$, e t $(29)=8,48, p<0,001$ ]

Foi possível identificar, também, o impacto da área de formação do profissional nas médias (gerais) de racionalidade $[F(2,67)=2,64, p=0,079$, MSE $=0,60, \eta p 2=0,073]$, já que engenheiros apresentaram maior desempenho que arquitetos $(p=0,079)$. Esse dado parece ser resultado do efeito das diferentes formações na habilidade de pensar logicamente (subescala "Habilidade Racional") $[\mathrm{F}(2,67)=3,72, \mathrm{p}=0,029$, MSE $=1,13, \eta p 2=0,10]$, considerando que os engenheiros tiveram maior pontuação que os arquitetos $(p=0,04)$.

Em relação ao desempenho geral em experiencialidade, os resultados mostram, mais uma vez, o impacto da área do profissional [F $(2,67)=10,01, p<0,001, \operatorname{MSE}=3,28, \eta p 2=0,23]$, mas indicam exatamente o oposto: arquitetos revelam maior média, se comparados a engenheiros $(0,001)$. Além disso, designers mostram uma tendência marginal a confiar mais no pensamento experiencial que os engenheiros $(p=0,066)$.

Especificamente em engajamento experiencial, as diferenças entre áreas são novamente evidentes $[\mathrm{F}(2,67)=12,82, \mathrm{p}<0,001$, MSE $=5,73 \eta p 2$ $=0,28]$ : arquitetos e designers tiveram maior média que engenheiros $(\mathrm{p}=0,001$ e $\mathrm{p}=0,003)$. Nas medidas de habilidade, da mesma forma, a formação do profissional interferiu nos resultados $[F(2,67)=5,64, p=0,005$, $\operatorname{MSE}=1,91 \eta p 2=0,14]$, indicando que o desempenho dos arquitetos foi significativamente superior ao dos engenheiros $(p=0,005)$, e o dos designers foi marginalmente menor que o dos arquitetos $(0,053)$.

\section{DISCUSSÃO DOS RESULTADOS}

A partir da pesquisa e dos resultados encontrados, foi possível estudar as diferentes interações entre projetistas e os problemas que a eles são apresentados. Dorst (2003) defende que não há como definir uma taxonomia dos problemas de design, pois eles nunca estão completos na cabeça de designers: são revelados e criados durante o processo. Dessa forma, o foco do autor passa a ser a definição de um modelo de como designers se aproximam de uma situação problemática, ao invés da definição de um modelo para problemas de design. Ao observar as outras áreas envolvidas em projetos, é possível imaginar que elas também lidam com inúmeros problemas durante o trajeto projetual, o que deve levar ao pensamento não linear apresentado por Baxter (2011). É importante ressaltar que, conforme Baxter (2011), o planejamento de produto começa com a estratégia de desenvolvimento e termina com especificações de produção de algo novo. É durante todo este processo que projetistas estarão 
criando e desenvolvendo formas para lidar com os problemas apresentados, seja através do uso da racionalidade ou da intuição.

É importante lembrar que o termo racionalidade não é entendido aqui como o oposto de intuição. Conforme apontando anteriormente, muitas vezes a decisão de utilizar uma impressão intuitiva na resolução de alguma etapa do processo projetual se dá de forma racional, devido a limitações impostas pelas informações disponíveis, pelo tempo de execução ou qualquer outra variável que pode ser considerada racionalmente pelo profissional. Também se destaca que, durante o desenvolvimento de um projeto de produto, ambos os sistemas (racional e experiencial) são utilizados diversas vezes em etapas distintas. É improvável que o projetista possua todas as informações necessárias para resolver todas etapas de projeto utilizando o raciocínio, uma vez que, como apontando por Dorst (2003) o problema evolui juntamente com sua solução.

A partir do estudo realizado observou-se que arquitetos favorecem a experiencialidade, enquanto engenheiros favorecem a racionalidade. Embora designers não tenham mostrado diferença significativa quando comparados a engenheiros e arquitetos, seus resultados na escala e nas subescalas de racionalidade estão entre os dos arquitetos e engenheiros, o que sugere que podem ser mais propensos a encontrar um equilíbrio na confiança em estilos diferentes de pensamento. Ou seja, designers mostraram que, quando se trata de julgar opções e tomar decisões, eles confiam em seus pensamentos analíticos, mas também utilizam experiências passadas e intuição. Além disso, podemos fazer um paralelo entre as duas rotas apresentadas por Cacioppo et al. (1986) para a tomada de decisão, os dois sistemas de Kahneman (2003) e os profissionais. A rota central, mais focada na decisão e na avaliação concreta, pode estar relacionada ao Sistema 2 (raciocínio). Através da pesquisa realizada observamos que apesar de todos utilizarem muito da racionalidade para tomar decisões, engenheiros se sobressaíram perante os outros, utilizando-a muito mais. Já a rota periférica, que conta com aspectos não tão relevantes para o problema, pode ser relacionada ao Sistema 1 (intuitivo). Este sistema foi utilizado pelos designers, que parecem buscar equilíbrio entre os estilos de tomada de decisão.

Énecessário ainda que se realizem mais pesquisas acerca do tema abordado neste artigo para que se possa compreender efetivamente de que forma o perfil e a formação acadêmica de um profissional influenciam na maneira como toma determinada decisão dentro de um processo de projeto de produto. Acreditamos que novos estudos deveriam ser realizados com maior número de profissionais, podendo assim levantar mais dados referentes à forma como o processo de projeto é realizado por pessoas de diferentes idades e com níveis de expertise variados. Uma vez que se tenha uma visão mais clara acerca desse tema, as consequências projetuais dessa influência também se tornarão mais claras e, dessa forma, mais passíveis de críticas construtivas diversas.

Os resultados deste estudo devem ser considerados no contexto de certas limitações metodológicas. Primeiramente, pois utiliza um delineamento de pesquisa transversal e deve ser considerado exploratório. Em segundo lugar, o pequeno tamanho da amostra impossibilita outros processos de refinamento, como uma análise estatística mais robusta. Em terceiro lugar, esses resultados estão limitados à amostra e não devem ser generalizados. Apesar dessas limitações, este estudo contribui de forma significativa para o conhecimento em torno da relevância da avaliação dos processos de tomada de decisão. Finalmente, assim como em todas as pesquisas voluntárias, existe o risco de um viés de autosseleção.

O destaque do estudo foi que uma busca on-line da literatura não encontrou outros estudos que relatam o uso do REI na comparação de arquitetos, engenheiros e designers, o que impede a comparação desses resultados. A maneira como profissionais tomam decisões necessita de uma investigação mais aprofundada. Além do mais, é importante compreender se os resultados durante o desenvolvimento de um novo produto seriam melhores caso os arquitetos, engenheiros e designers utilizassem mais seus sistemas racional e experiencial. Por último, a compreensão da relação entre 
as escalas REI e a emocionalidade poderia se beneficiar de uma investigação mais aprofundada.

\section{CONCLUSÃO}

Através do estudo realizado e da revisão teórica utilizada, algumas considerações importantes podem ser feitas: os diferentes profissionais que participaram do estudo, como suposto, possuem formas diversas de lidar com a incerteza durante o processo de tomada de decisão. Arquitetos favorecem a experencialidade, enquanto engenheiros utilizam mais a racionalidade. Já designers, por outro lado, não apresentaram diferença significativa quando comparados aos outros dois tipos de profissionais, apresentando maior equilíbrio quanto aos estilos de pensamentos utilizados.

$O$ resultado encontrado sugere que as pessoas que podem e confiam mais no pensamento racional também estão sujeitos a ter pensamentos irracionais ou, talvez, estar em conflito sobre o que é racional e qual é o valor da experiência. A forma como cada categoria profissional processa informações, avalia os dados disponíveis e toma decisões pode ser influenciada pela maneira como o projeto e produto irão ser desenvolvidos. Por essas razões, é crucial identificar quais sistemas de decisão são utilizados durante o desenvolvimento de um novo produto.

\section{AGRADECIMENTOS}

Os autores deste artigo agradecem o apoio do Conselho Nacional de Desenvolvimento Científico e Tecnológico (CNPq) e da Coordenação de Aperfeiçoamento de Pessoal de Nível Superior (Capes).

\section{REFERÊNCIAS}

BAXTER, M. R. Projeto de produto: guia prático para o design de novos produtos. Tradução Itiro lida. São Paulo: Edgard Blücher, 2011.

BONSIEPE, G. Metodologia experimental: desenho industrial. Brasília, DF: CNPq; Coordenação Editorial, 1984.

CACIOPPO, J. T et. al. Central and peripheral routes to persuasion: an individual difference perspective. Journal of Personality and Social Psychology, Washington, DC, v. 51, n. 5, p. 1032-1043, 1986.

DORST, K. The problem of design problems. In: DESIGN THINKING RESEARCH SYMPOSIUM, 6., 2003. Proceedings... Sydney: Sydney University of Technology, 2003.

EPSTEIN, S. Integration of the cognitive and the psychodynamic unconscious. American Psychologist, Washington, DC, v. 49, n. 8, p. 709-724, ago. 1994.

Valentina Marques da Rosa valentina.rosa@hotmail.com

Roberta Rech Mandelli beta.mandelli@gmail.com

Priscila G. Brust-Renck prirenck@gmail.com

Leandro Miletto Tonetto Itonetto@gmail.com
KAHNEMAN, D. A perspective on judgment and choice: mapping bounded rationality. American Psychologist, Washington, DC, v. 58, n. 9, p. 697-720, set. 2003.

PACINI, R.; EPSTEIN, S. The relation of rational and experiential information processing styles to personality, basic beliefs, and the ratio-bias phenomenon. Journal of Personality and Social
Psychology, Washington, DC, v. 76, n. 6, p. 972-987, 1999.

RITTEL, H. W. J.; WEBBER, M. M. Dilemmas in a general theory of planning. Policy Sciences, Dordrecht, v. 4, n. 2, p. 155-169, 1973.

SCHÖN, D. A. Educando o profissional reflexivo: um novo design para ensino e aprendizagem. Porto Alegre: Artmed, 2000.

SIMON, H. A. The sciences of the artificial. Cambridge: The MIT Press, 1996.

SLOMAN, S. A. The empirical case for two systems of reasoning. Psychological Bulletin, Washington, DC, v. 119, n. 1, p. 3-22, 1996.

STANOVICH, K. E.; WEST, R. F. Natural myside bias is independent of cognitive ability. Thinking and Reasoning, Abingdon, v. 13, n. 3, p. 225-247, 2007.

TURNER, B. M. et al. The maximization inventory. Judgment and Decision Making, Philadelphia, v. 7, n. 1, p. 48-60, 2012.

VOLPENTESTA, A. P.; AMMIRATO, S.; SOFO, F. Thinking style diversity and collaborative design learning. IFIP Advances in Information and Communication Technology, Heidelberg, v. 307, p. 785-796, 2011 